\title{
Breakthrough of Ginokgobiloba with Nutritions; Iron Zinc, Iodine, Pantothenic Acid
}

\author{
HM Rafeek* \\ Complementary \& Alternative Medicine, Sri Lanka
}

*Corresponding author: HM Rafeek, Consultant Complementary \& Alternative Medicine Specialist in Pain Management, Sri Lanka.

Received Date: September 26, 2019

Published Date: September 30, 2019

\section{News}

In spite of the substantial advances that have been made in synthetic, organic chemistry. plant products still remain as an integral part of the modern therapy. This extract of the ginokgobiloba are today widely used in western country and Asia. This is a huge success in terms of treating brain, vascular disease and erectile dysfunction. Ginokgobiloba is now cultivated as an ornamental tree in streets, parks and throughout the world for its extra ordinary beauty and medicinal properties.

Particularly in Germany, France, Korea, united states and Asian country. The part of the plant which is used today for medicinal purpose are; fan shaped bilobate leaves which must be collected green during the summer. As far as the flavonoids are concerned, these class of compounds have isolated, namely, dimeric flavonoids quercetin kaempferol, iso-rhamentim and there glycoides, oligomeric and polymeric procyanidins. In the extract of therapeutic interest, the dimeric flavonoids are present only in small amounts as well as mono-glycosides, the main compounds are di-glycosides which can be esterified or not with coumaric acid in position with $\mathrm{C} 6$ of the glucose moiety. As far as medicinal use of the ginokgobiloba, this plant has long been part of the traditional Chinese pharmacopoeia, being first sighted and used as a medicinal agent for over 5000 years and has been considered for long time the part of youth, for the general tonic properties.

Note: ginokgobiloba extract $120 \mathrm{mg}$ equals to approximately 6000 leaves of ginokgobiloba

Due to the plants extremely low toxicity, the extract was tested for the ability to improve central and peripheral circulatory disorders, its proved increase blood flow in large number of diseases. Clinically, we have had certain patients with lower limbs circulatory disorder, cerebral insufficiency, headaches, memory loss, drop of vigilance and concentration, liability of mood, trouble of sociability, confessional states. and I have treated a number of patients with the corresponding symptoms and have had many positive results.

Peripheral vascular disorders such as idiothetic, cylicoedemas and arterial disease, lower limb associated in walking pain, not only that, it's also helpful in Psychic and behavioral old age disorder in some cases.

Clinically, we observed the effeteness of ginokgobiloba extract individual patients and patients to patients, we noticed that it improved the blood flow to the hands, legs and feet. Ginokgobiloba can be recommended to use on daily basis as a supplement which benefits in improving the peripheral vescular blood flow in atherosclerosis (hardening of the arteries).

I have seen some patients who are suffering in their calf muscles, and lack of oxygen which results as a painful type of cramp which is called as intermittent claudication.it occurs mostly in calf muscles and it is felt while walking. I have noticed this type of patients are very responsive to ginokgobiloba extract and it is very effective. The ginokgobiloba herbs act on vasomotor response easily demonstrated in healthy subject at the level of the skin; face, fingertips, nail fold and some skin conditions with a good outcome.

In most of the country, specially neuro physicians and health care practitioners use ginokgobiloba. This happens to be the number one health product in Sweden, Great Britain and Asia. I like to suggest here that this product mostly focuses on nervous system and phycological function, and some case vascular disorder. Apart from that, it also helps in dermatological benefits. 


\section{Acknowledgement}

None.

\section{Conflict of Interest}

No conflict of interest. 